\title{
A GENERAL EXISTENCE THEOREM FOR THE SINGULAR EQUATION $\left(\varphi_{p}\left(y^{\prime}\right)\right)^{\prime}+f(t, y)=0$
}

\author{
HAISHEN LÜ AND DONAL O'REGAN
}

Abstract. Some theorems concerning the existence of positive solution for the singular equation $\left(\varphi_{p}\left(y^{\prime}\right)\right)^{\prime}+f(t, y)=0, y(0)=y(1)=0$, are established. The results are obtained using the lower-upper solution approach.

\section{Mathematics subject classification (2000): 34B15.} method.

Key words and phrases: One-dimensional singular equation, Positive solution, Lower-upper solution

\section{REFERENCES}

[1] K. Deimling, Nonlinear Functional Analysis, Springer-Verlag, 1985.

[2] H. G. KAPER, M. KNAPP AND M. K. KWONG, Existence theorems for second order boundary value problems, Differential and Integral Equations, 4 (1991), 543-554.

[3] M. A. HeRRERO AND J. L. VAZGUEZ, On the propagation properties of a nonlinear degenerate parabolic equation, Comm. Partial Differential Equations, 7 (1982), 1381-1402.

[4] J. R. ESTEBAN AND J. L. VAZGUEZ, On the equation of turbulent filtration in one-dimensional porous media, Nonlinear Anal., 10 (1986), 1303-1325.

[5] Donal O'Regan, Some general existence of principles and results for $\left(\phi\left(y^{\prime}\right)\right)^{\prime}=q(t) g\left(t, y, y^{\prime}\right)$, $0 \leqslant t \leqslant 1$, SIAM J. Math. Anal., 24 (1993), 648-668.

[6] Donal O'REgan, Existence theory for $\left(\phi\left(y^{\prime}(t)\right)\right)^{\prime}=q(t) g\left(t, y, y^{\prime}\right), 0 \leqslant t \leqslant 1$, Communications in Applied Analysis, 1 (1997), 33-52.

[7] M. D. Pino, M. Elgueta AND R. MANÁSEVICH, A homotopic deformation along $p$ of a Leray-Schauder degree results and existence for $\left(\left|u^{\prime}\right|^{p-2} u^{\prime}\right)+f(t, u)=0, u(0)=u(1)=0, p>1$, J. Differential Equations, 80 (1989), 1-13.

[8] R. MANÁSEVICH AND F. ZANolin, Time mapping and multiplicity of positive solutions for the one dimensional p-Laplacian, Nonlinear Analysis, 21 (1993), 269-291.

[9] A. CABADA AND R. L. POUSO, Existence results for the problem $\left(\phi\left(u^{\prime}\right)\right)^{\prime}=f\left(t, u, u^{\prime}\right)$ with nonlinear boundary conditions, Nonlinear. Anal., 26 (1996), 925-931.

[10] C. De Coster, Pairs of positive solution for the one-dimensional p-Laplacian, Nonlinear. Anal., 23 (1994), 669-681.

[11] YAO QINGLIU AND LÜ HAISHEN, Positive solutions of one-dimensional singular p-Laplace equations, Acta Mathematica Sinica, 41 (1998), 1255-1264. 